We are gradually learning that "user experience" is a critical factor in customer satisfaction and loyalty. A positive experience means a happy customer who returns again. Designers of software systems and web services have been digging deeply into how they might generate a positive user experience. They are moving beyond anecdotes about excellent examples of user experiences and are developing design principles. Phillip Tobias gives us a fascinating account of the emerging design principles that will generate satisfied and loyal users.

Peter Denning

Editor

\title{
Is Design the Preeminent Protagonist in User Experience?
}

\author{
Phillip Tobias \\ Kutztown University of Pennsylvania \\ Computer Science Department \\ ptobi435@kutztown.edu
}

\author{
Dr. Daniel S. Spiegel \\ Kutztown University of Pennsylvania \\ Computer Science Department \\ spiegel@kutztown.edu
}

Think of one of your favorite items and imagine it right in front of you. You can probably describe it in great detail to someone. However, try to describe it without mentioning or referring to colors, shapes, text, or any other visual elements. This is a challenging task, and attempting to describe any item to someone in this manner most likely will cause ambiguity and confusion. Subconsciously, we create an embedded image in our mind based on an item's appearance or brand. Dick Berry in "The user experience" denotes this embedded image as a user's mental model or conceptual model [2]. A user interacts with physical items, builds up experiences, and as a result creates a mental model over time. This mental model can contribute to the success of product marketing and software. At the rapid rate of progression of technology, the acceptance of software with identical functionality can come down to user experience. A product can leverage itself above the rest by the superiority of its design. This article will discuss the emphasis on design as a primary vehicle for strategy, flow, and affordance as it pertains to user experience in a device or system.

\section{User Experience}

When a system is well implemented, there is no need to question how to interact with it. A user can easily navigate through the system and feel confident in their decisions leading them to become so absorbed in this interaction that they lose sense of time by each rewarding action. This phenomenon occurs during use of various forms of media and devices, such as web sites, software, kiosks, and mobile devices among many others, and constitutes a facet of the Human Computer Interaction $(\mathrm{HCl})$ discipline known as user experience. User experience, often abbreviated as UX, encompasses many fields including, but not limited to, psychology, interaction design, interface design, and usability. One issue with UX though is a clear-cut definition. When describing user experience, we are doing just that, describing one's experience. Yet, many factors are taken into account when describing or storytelling an experience because each individual may have different expectations of objects, leading to varying perceptions of the success and pleasurability of use.

In April 2008, a Special Interest Group at the CHI 2008 proceeding presented a paper entitled, "Towards a Shared Definition of User Experience." [10] The authors of this paper presented a list of definitions of UX from various individuals and organizations in the field with each definition much different from the others. Figure 1 lists a few of those UX definitions.

\begin{tabular}{|l|l|}
\hline Lauralee Alben: & $\begin{array}{l}\text { All the aspects of how people use an interactive product: the way it feels in their } \\
\text { hands, how well they understand how it works, how they feel about it while they're } \\
\text { using it, how well it serves their purposes, and how well it fits into the entire context } \\
\text { in which they are using it. [1] }\end{array}$ \\
\hline Nielsen Norman Group: & $\begin{array}{l}\text { All aspects of the end-user's interaction with the company, its services, and its } \\
\text { product [13]. }\end{array}$ \\
\hline $\begin{array}{l}\text { Marc Hassenzahl } \\
\text { \& Noam Tractinsky: }\end{array}$ & $\begin{array}{l}\text { A consequence of a user's internal state (predispositions, expectations, needs, } \\
\text { motivation, mood, etc.), the characteristics of the designed system (e.g. complexity, } \\
\text { purpose, usability, functionality, etc.) and the context (or the environment) within } \\
\text { which the interaction occurs (e.g. organizational/social setting, meaningfulness of } \\
\text { the activity, voluntariness of use, etc.) [8] }\end{array}$ \\
\hline
\end{tabular}


Without exhaustive inquisition, it is clear that UX does not have a universally accepted definition. In spite of this, it is reasonable to assume widespread agreement on several aspects of UX. Clearly, UX is a feeling a user has while interacting with a device or system. In addition, UX is an attitude towards a system and an emotional bonding with a system. It must be noted, however, that judgment regarding whether a particular implementation is the most pleasing experience for a device or system is open to interpretation. What can be concluded is that UX is a class of theories and heuristics. Furthermore, UX involves an extensive range of systems and devices. How a user experiences a web site is considerably different from how they experience television. Each involves a unique environment with various contributing factors. For instance, a web site typically involves interaction by mouse clicks, scrolling, and keystrokes in close range to a screen while a television typically involves a user with a remote control consisting of a series of numbers, arrows, and menu options that operates at a distance from the set. These factors lead to different implementations since different factors are considered in their design. Nonetheless, UX affects a system from start to finish. Jesse James Garrett states in his book, The Elements of User Experience [6]:

Businesses have now come to recognize that providing a quality user experience is an essential, sustainable competitive advantage. It is user experience that forms the customer's impression of the company's offerings, it is user experience that differentiates the company from its competitors, and it is user experience that determines whether your customer will ever come back.

Researchers at Carleton University in Ontario conducted a study that demonstrated that users formulate impressions of a web site in the first 50 milliseconds of viewing [11]. In this brief initial snapshot, a user is not given adequate time to read content or test a web site's functionality; their initial perception is based solely on its design. Their impression further affects what psychologists denote as the halo effect, or a cognitive bias where one's thoughts are swayed by their past impressions. Users may tend to ignore minor faults and evaluate the site's content more favorably if at first glance a user's reaction is a positive experience.

There can be no doubt that one factor contributing to UX is design. By leveraging design an experience can become more engaging, invoking a much grander experience and positively influencing the user's mental model. This article will examine three components of UX: strategy, flow, and affordance, and the psychological underpinnings of design in each.

\section{Strategy}

Before embarking on a large project, significant planning must occur. This includes going over project goals and the best plan of attack or strategy for a system. Michael Porter, a University Professor at Harvard Business School and key advocate of strategy, states that, "The essence of strategy is choosing what not to do." [14] By knowing what not to include, what must be included can be better determined. From here, one can plan with objectives, declaring each with a clear purpose and reasoning for the strategy. For instance, if a design currently exists for a system, is there a need for full redesign or will realignment be more appropriate? Cameron Moll, in his article "Good Designers Redesign, Great Designers Realign," [12] discusses the differences between redesigning and realigning. Redesign is more aesthetically driven. It is starting over, leaving little from the current design intact. On the other hand, realignment is purpose-driven. At times, the application of strategy doesn't require an entire makeover, rather, it can be an update based on the change of times and/or technology. With a fitting strategy, any required retooling can be addressed based on growth and new opportunities in design.

These strategic concerns additionally impact branding, a vital component in a situation where a product is marketed to establish recognition. A brand is like a catchy hook, or distinctive progression, that is psychologically pleasing in a song. It seizes attention and begins to characterize a user's conceptual model, making branding a significant aspect to consider.

More importantly, the concept of strategy, in the $\mathrm{HCl}$ community, is the act of building the best conversation between human and computing device. This entails creating and sustaining positive interaction. Bickmore and Picard state that knowledge of human social psychology on the role of the concept simply termed affect is central in building relationships in the most natural manner possible [3]. Still, strategy is only one component design influences that benefits quality user experiences. Captivating the user is another, and this is accomplished by design that occupies the user's attention. 


\section{Flow}

You begin reading a novel with an engrossing narrative in which the characters act out each sentence you read in your mind. You learn of their intricacies and unique behaviors. Within what seems as just a few moments in passing, you reach the denouement. In actuality, an hour or more passes and you complete the book. Flow is experienced by the reader of a well written, engrossing novel. Psychologist Mihaly Csikszentmihalyi defines flow as a psychological state of complete absorption with an activity [5]. For a system, Ramsey states that flow makes the system feel painless to use regardless of its true complexity [15]. The term flow approaches user experience explicitly in that it occurs in an actual experience. Csikszentmihalyi states the nine dimensions of flow:

1. Clear goals

2. Concentrating and focusing

3. A loss of feeling of self-consciousness

4. Distorted sense of time

5. Direct and immediate feedback

6. Balance between ability level and challenge

7. A sense of personal control

8. The activity is rewarding

9. Merging of action and awareness

One may encounter each of these when interacting with a system. To get this experience, or flow, there needs to be some form of design, where the position of elements constructs the optimal user experience.

A user's flow can be impeded when a device presents a contradiction, or dissonance, between a user's conceptual model of an object and what is presented. By limiting cognitive friction flow helps new users get up to speed more quickly by using design to minimize any contradictions in a system. For example, a kiosk involving a form that asks users' opinions is presented over several slides. Besides the fields and questions in the form, each slide contains two buttons with the words cancel and continue. If color was included as part of the form's design, then intuitively, the button labeled cancel would likely be a shade of red, which represents a sense of protection from anxiety. The continue button would likely be colored green, which alleviates anxiety and offers a sense of self-control. Each color aids in representing its button's purpose because of a user's previous cognitive bias, perhaps previously influenced by the colors of a traffic light. Contradictions can be further diminished by affordances too, which will be discussed later.

Flow, properly incorporated into a web site, also reduces the chance of users leaving. In addition, Ramsey claims flow increases activity and creates a greater awareness of the site. Studies on flow have found it leads to "increased learning, exploratory and positive behavior, positive subject experience, and perceived sense of control over their interaction", as shown by King [9]. Web traffic can rise as a result of a successful design of flow in an application, which builds a positive experience. To fully grasp flow requires gaining an understanding of the elements it comprises. In particular, flow is a product of its constituent affordances.

\section{Affordance}

Consider a successful novel or television series. They often involve grounded characters, whose actions and perceptions mirror ours. People can relate to these characters and see themselves in their situations. These characters are a key component to a well-written story. They are identifiable by quotable phrases and how they respond to particular scenarios. We come to develop expectations regarding the actions and thoughts of the characters, which is precisely how we react to others in our own lives. This same idea can be applied in user experience by the perceived expectations of objects and their conventions. For instance, people use scissors to cut, people use glue to paste two objects together, and people have a perceived understanding of the elasticity of a rubber band. In this article, the term affordance is used in the way J. J. Gibson uses the term as a stimulusresponse connotation. Gibson refers to affordance as "whatever it is about an object that contributes to the kind of interaction" [7]. For example, a button slightly raised above a flat surface suggests the idea of pushing it. The affordance is not inherent to the button but to the characteristic that suggests its functionality.

Characteristics such as these are simple design decisions that facilitate creation of relations in a user's mental model in the same manner that certain characters are more likeable in a novel because one can relate to them. It is easier to understand a likable character's thoughts and actions then it is for a character that one has difficulty relating to. Another example is a switch involving a lever. The lever protruding out at a down angle 
affords, or allows, for pushing it up. If it is out to the right, the apparent affordance is to push it to the left. The affordance of an object is an intuitive implication of its function. Affordances are perceived because of their appearances. A text link on a web site is typically blue and underlined. If the link were identical to the context on the page, it would be difficult to perceive it as a clickable link. A button on a web page gives the appearance of being pushed by highlighting the opposite borders relative to those of an unpushed button. The states of an unpushed and pushed button can be seen in Figure 2.

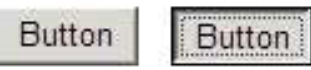

Figure 2: An unpushed (Left) and pushed (right) HTML button

Affordance, pertaining to $\mathrm{HCl}$, is a social cue in a computerized world. It is visible by design because of the elements present or absent in an object.

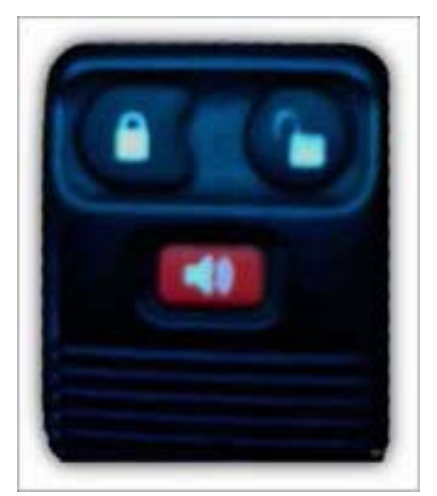

Figure 3: Keyless car entry

\section{Example - Keyless Car Entry}

To gain a better understanding of how design directly impacts user experience, consider a keyless car entry as shown in Figure 3. This product is a small compact device allowing remote interactions with an automobile. Usually consisting of three buttons, lock, unlock, and alarm, a keyless entry's small lightweight design makes it capable of easily being attached to a set of keys and fit in a pocket. But it is the design of this device that plays an integral part in its popularity.

A user is unaware of the underlying logic that executes when locking a car door, but has a clear expectation when pressing a button displaying a closed lock icon. Although the flow of using a keyless entry is brief, the interaction yields a positive experience. Over time, owners may find the interaction of a keyless entry becomes implicit, adhering to Csikszentmihalyi's nine dimensions of flow. It follows that the affordances of a keyless entry could not be clearer.

Each button of the device is designed to be slightly raised or recessed and a comfortable size for the tip of a finger, affording it to be easily and accurately pushed. On many of these devices, the buttons are also of a unique shape. The icon presented on each button creates a clear distinction of its purpose that transcends spoken or written language. A lock displayed in the state of being open and closed represents unlocking and locking doors, respectively. A speaker projecting sound signifies an alarm. The alarm button is further distinguished with a visual cue: use of the color red in its icon.

Without design it is difficult to imagine how to effectively convey a keyless entry's purpose. The design of the labels and icons on the buttons give clear indication of the intention of each button, and additionally the urgency of the alarm. A keyless entry without these attributes would enjoy far less acceptance, as its intuitive appeal becomes more about trial-and-error for a user, requiring them to tutor themselves. In all, the compact design, innate control, and clear affordances of a keyless entry keep users satisfied generating a positive experience. It must also be emphasized that even if the user memorizes the placement of the buttons, it is the affordances described that permit them to locate and activate the desired button without even looking at the device. 


\section{The Voice of UX}

User experience may differ entirely from one user to another. Catriona Cornett of inspireUX agrees, noting, "Defining 'user experience' and the disciplines within it is a common source of debate amongst UX designers." [4]. Her site, http://www.inspireuX.com/, provides quotes on the impact of UX from individuals involved in UX. Each quote describes the importance of a positive user experience. Below are two examples.

"Design creates stories, and stories create memorable experiences, and great experiences have this innate ability to change the way in which we view our world." -Christian Saylor

"Your products run for election every day and good design is critical to winning the campaign." A.G. Lafley

Until a clear definition of UX is agreed upon, the effort made by designers and developers can't be fully assessed or appreciated. Furthermore, without design a system becomes increasingly difficult when progressing from beginning to end. By leveraging design, one's experience becomes more enjoyable and easily evangelized. Design shapes a customer's perception of a brand, aiding the user's mental model. As a result of a good UX design, a user experiences a subconscious give and take of emotions, developing an attitude and emotional bonding based on their experience.

\section{Conclusion}

User experience is not just a result of UX design; rather, design directly affects user experience. Other components, such as usability, interaction design, interface design, and so forth are all still important to the equation; however, the premise of this article presents design as a much greater factor. Without design it becomes difficult to imply an object's functionality specifically in a device or system. In all, design is what drives user experience, which in turn affects the user's mental model. The absence or lack of design formulates an equation with an essential variable missing. Leveraging design not only impacts the user psychologically, but also directly affects user experience in $\mathrm{HCl}$ making design the central figure for $\mathrm{UX}$, and thus the protagonist.

\section{References}

[1] Alben, Lauralee. Quality of experience: defining the criteria for effective interaction design. Interactions 3. 1996.

[2] Berry, Dick. The user experience. 1 Oct. 2000. IBM. 2 Sept. 2008.

http://www.ibm.com/developerworks/library/w-berry.

[3] Bickmore, T. W. and Picard, R. W. 2005. Establishing and maintaining long-term human-computer relationships. ACM Trans. Comput.-Hum. Interact. 12, 2 (Jun. 2005), 293-327. DOI= http://doi.acm.org/10.1145/1067860.1067867

[4] Cornett, Catriona. inspireUX. 17 Nov. 2008. http://www.inspireux.com/about/.

[5] Csikszentmihalyi, Mihaly. Beyond Boredom and Anxiety: Experiencing Flow in Work and Play. Jossey-Bass. 2000.

[6] Garret, Jesse James. The Elements of User Experience. New Riders Press. 2002.

[7] Greeno, James G. Gibson's Affordance. Psychological Review. 1994, Vol. 101, No.2 336-342.

[8] Hassenzahl, Marc, and Noam Tractinsky.. "User experience - a research agenda." Behaviour \& Information Technology 25.2 (Mar. 2006): 91-97. Computers \& Applied Sciences Complete. EBSCO. Rohrbach Library, Kutztown, PA. 3 Nov. 2008 http://navigatorkutztown. passhe.edu/login?url=http://search.ebscohost.com/login.aspx?direct=true\&db=iih\&AN=19277 459\&site=ehost-live \&scope=site . 
[9] King, Andrew. Website Optimization: Speed, Search Engine \& Conversion Rate Secrets. O'Reilly Media, Inc. 2008.

[10] Law, Effie, et al. Towards a shared definition of user experience. New York. 2008.

[11] Lindgaard G., G. Fernandes, C. Dudek, and J. Browntilde. Attention web designers: You have 50 milliseconds to make a good first impression! Behaviour \& Information Technology, 25:115-126, 2006.

[12] Moll, Cameron. Good Designers Redesign, Great Designers Realign. 24 Oct. 2005. A List Apart Magazine. 4 Sept. 2008. http://www.alistapart.com/articles/redesignrealign.

[13] Nielson Norman Group. User Experience - Our Definition. 11 Nov. 2008.

http://www.nngroup.com/about/userexperience.html.

[14] Porter, Michael. What is strategy? Harvard Business Review, Nov/Dec 1996, vol. 74 no 6.

[15] Ramsey, Jim. Designing For Flow. 4 Dec. 2007. A List Apart Magazine. 4 Sept. 2008. http://www.alistapart.com/articles/designingforflow. 